This is the final peer-reviewed accepted manuscript of:

Buratti, N., Minghini, F., Ongaretto, E., Savoia, M., and Tullini, N. (2017) Empirical seismic fragility for the precast RC industrial buildings damaged by the 2012 Emilia (Italy) earthquakes. Earthquake Engng Struct. Dyn., 46: 2317- 2335

The final published version is available online at: https://doi.org/10.1002/eqe.2906

Rights / License:

The terms and conditions for the reuse of this version of the manuscript are specified in the publishing policy. For all terms of use and more information see the publisher's website.

This item was downloaded from IRIS Università di Bologna (https://cris.unibo.it/)

When citing, please refer to the published version. 


\title{
Empirical seismic fragility for the precast RC industrial buildings damaged by the 2012 Emilia (Italy) earthquakes
}

\author{
Nicola BURATTI ${ }^{\mathrm{a}}$, Fabio MINGHINI ${ }^{\mathrm{b}}$, Elena ONGARETTO ${ }^{\mathrm{a}}$, \\ Marco SAVOIA ${ }^{\mathrm{a}}$, Nerio TULLINI ${ }^{\mathrm{b}}$ \\ a Department of Civil, Chemical, Environmental, and Material Engineering (DICAM), \\ University of Bologna, Viale Risorgimento 2, Bologna, Italy \\ ' Department of Engineering, University of Ferrara, Via Saragat 1, Ferrara, Italy \\ "Corresponding author. E-mail: fabio.minghini@unife.it
}

\begin{abstract}
The paper analyses the seismic fragility of precast RC buildings using observational damage data gathered after the 2012 Emilia earthquakes that struck Northern Italy. The damage level in 1890 buildings was collected, classified, and examined. Damage matrices were then evaluated and finally empirical fragility curves were fitted using Bayesian regression. Building damage was classified using a six level scale derived from EMS-98. The completeness of the database and the spatial distribution of the buildings investigated were analysed using cadastral data as a reference. The intensity of the ground-motion was quantified by the maximum horizontal peak ground acceleration (PGA), which was obtained from shakemaps.
\end{abstract}

Keywords: Precast RC buildings; Seismic damage; Seismic fragility; Seismic risk; Emilia earthquakes.

\section{INTRODUCTION}

In present economy, seismic loss estimation is extremely important for planning civil protection strategies and for predicting costs for restoring or retrofitting damaged buildings after earthquakes. Fragility curves are a fundamental tool for seismic risk assessment. These curves relate the probability of exceeding a particular damage level to ground-motion intensity [1]. They can be obtained using different approaches, mainly statistical analysis of observational damage data or numerical modelling.

Observational damage data from past earthquakes are commonly used worldwide for the development of new empirical fragility curves or for validating existing ones based on mechanical models. D'Ayala et al. [2] used damage data from the 1755 Lisbon (Portugal) earthquake for estimating fragility functions suitable for Europe's historic city centres. Yamaguchi and Yamazaki [3] developed fragility functions for five different building typologies in Japan using damage data from the 1995 Kobe earthquake. Rossetto and Elnashai [1] derived empirical vulnerability curves for reinforced concrete (RC) buildings from 99 datasets collecting field observations from 19 earthquakes and including about 340000 buildings. Karababa and Pomonis [4] obtained a set of vulnerability curves for five building typologies in Lefkada Island, Greece. In their proposal, the authors used damage data collected after the earthquake that occurred in the island on August 14, 2003, and related the vulnerability of the buildings to the Parameterless Scale of Seismic Intensity (PSI) [5, 6]. Molina et al. [7] recently used a damage database concerning about 67500 buildings struck by the 2010 Haiti earthquake for calibrating vulnerability curves for the city of Port-au-Prince. For the same destructive event, new fragility functions based on two separate methods of damage assessment, including field surveys and remote sensing, were obtained in [8]. With reference to Italian buildings, mainly comprised of low- to mid-rise masonry and RC structures, Rota et al. [9] proposed typological fragility curves based on earthquake damage data collected in the past 30 years. In Ref. [10], the possible sources of uncertainty that can affect empirical vulnerability curves were identified, such as the errors in ground shaking prediction and building exposure, the use of census data to establish the number of buildings in each municipality for each building typology, the incompleteness and deficiencies in survey forms, and the errors in data post-processing. For a recent, comprehensive review of the existing empirical fragility functions, see Ref. [11]. 
When numerical procedures are used to evaluate the seismic fragility of structures, damage is generally estimated using results obtained from numerical models. In nonlinear analysis methods, the attainment of a particular damage level, corresponding to a given limit state, can be defined in terms of material strains [12, 13], interstorey drifts or chord rotations [14], and other Engineering Demand Parameters [15]. Although the analysis method influences the vulnerability assessment of structures, Silva et al. [16] showed that, for a given structural typology, fragility curves are not particularly sensitive to the type of numerical analysis adopted. Of course, in order to be able to make reliable predictions, numerical models must be able to represent all the possible damage mechanisms that can affect the category of buildings under consideration, as well as possible inhomogeneities and irregularities. This aspect is crucial, for instance, for masonry structures, where both local and global collapse mechanisms must be captured by models, but also for precast RC industrial buildings. In fact, the dynamics of these structures can be strongly affected by infill walls or intermediate floors covering only a limited portion of the plan. These elements, because of limited structural redundancy, can facilitate the onset of failure mechanisms. For these reasons, observational models based on field results are very important to assess and calibrate numerical prediction models.

The present paper focuses on the definition of observational fragility curves for RC precast buildings using damage data collected after the Emilia seismic sequence that struck the north of Italy in 2012. In this sequence, two main shocks can be identified: the 20 May earthquake, with $\mathrm{M}_{\mathrm{w}}=6.1$, and the 29 May earthquake, with $\mathrm{M}_{\mathrm{w}}=6.0$.

The region struck by these earthquakes is one of the most productive areas in Italy, and is characterized by medium-to-small industrial zones, located in various municipalities. The number of industrial buildings located in the Emilia-Romagna region is almost 80000, corresponding to approximately $12 \%$ of the industrial buildings in Italy $[17,18]$. Most of the precast RC buildings in Emilia have a single-storey structure, typically made of a series of simple portal frames. Each frame is comprised of columns clamped on either cast in place or precast pocket foundations [19], main beams simply-supported on the column tops, and precast slab elements, also simply-supported on the main girders. Some buildings might have two floors or intermediate floors in specific areas, typically along one of the two short edges, where offices are usually located. Up until 10 years ago, the region was not considered as a seismic area by building codes, therefore beam-column and slab-beam supports were typically friction-based, without mechanical connectors to prevent large relative displacements or loss of support failures during seismic ground-motions.

After the 2012 seismic events, the vulnerability of industrial precast buildings drew much attention from the research community. In Ref. [20], a review of the precast structural typologies and construction practice in Northern Italy was presented, and, for industrial buildings located in Tuscany and in Emilia (with some of them struck by the 2012 earthquake sequence), the probabilistic distributions of some geometrical characteristics, such as column height, span length of main girders and roof slab elements were obtained. The total number of precast RC buildings included in that study is 670 , with 40 located in Emilia. The authors reported that more than $85 \%$ of the 40 buildings struck by the Emilia earthquake were built without suitable seismic design rules. Finally, by means of a series of Finite Element (FE) nonlinear static and dynamic analyses, the authors evaluated the seismic fragility of the building stock in terms of spectral acceleration. The methodology has recently been extended by Casotto et al. [21], who defined an automated procedure for generating series of precast RC structures compatible with the properties of the building stock through a probabilistic characterization of material and geometrical building properties. The damage levels, related to loss of support, column bar first yielding, and flexural collapse limit states, were estimated through both 2D and 3D nonlinear FE models.

The present paper presents the damage data collected by the authors, using both field surveys and technical reports prepared for obtaining public funds for reconstruction. The distribution of the buildings for which damage data were collected is analysed using cadastral data as a reference. Damage data are then used to define damage matrices from which empirical fragilities are estimated. Finally, parametric fragility curves for the different damage states under consideration are fitted using a Bayesian approach. Two main categories of models are adopted: fragility models based on the exceedance of individual damage states, and ordinal models that maintain ordinality among the fragility of damage states. The uncertainty on the ground-motion estimate is discussed and included in the ordinal model. When compared with fragility curves for RC buildings reported in the literature, 
the results presented here show that Italian precast structures for industrial-buildings are characterized by much higher seismic vulnerability than cast-in-place RC frame structures and therefore require specific fragility models.

\section{DAMAGE DATABASE FOR INDUSTRIAL BUILDINGS AFTER THE EMILIA EARTHQUAKES}

Damage data were collected for a vast region around the epicentres of the earthquakes that struck Emilia in 2012. The region of interest, considered in the present paper, was identified according to the definition introduced by the Legislative Decree no. 74/2012 [22]. The boundaries of this area were defined as the envelope of circles with a radius of $10 \mathrm{~km}$ centred on the epicentres of all the earthquakes with $\mathrm{M}_{\mathrm{L}} \geq 3.5$ [23]. The resulting area is approximately $100 \mathrm{~km}$ long (E-W) and $40 \mathrm{~km}$ wide $(\mathrm{N}-\mathrm{S})$ and includes 52 municipalities, 35 of which are in the Emilia-Romagna region.

\subsection{Typological features of the precast industrial buildings in the area of interest}

A review of the main typologies of precast structures used in Italy since the 70 s is presented in [24, 25]. According to Ref. [18], approximately $70 \%$ of the industrial buildings in the Emilia-Romagna region are single-storey precast RC structures. For the industrial buildings struck by the 2012 Emilia earthquakes, two main categories of precast RC structures were identified in Ref. [26]: 1) buildings constructed from 1970 to 1990 (Type 1), featuring double slope beams with spans from 12 to $20 \mathrm{~m}$, roof slabs spanning from 6 to $10 \mathrm{~m}$, and masonry infills; ii) buildings constructed after 1990 (Type 2 ), with significantly longer spans of beams and roofing elements, and either horizontal or vertical prefabricated RC cladding panels. These two building types approximately correspond to those subsequently adopted by Casotto et al. [21]. Furthermore, in Ref. [21] the two building categories, also named Type 1 and Type 2, were characterized by means of probability distributions for the main geometrical parameters (see Table 1).

Table 1. Geometrical dimensions used by Casotto et al. [21] for the generation of their industrial building stock.

\begin{tabular}{llllll}
\hline $\begin{array}{l}\text { Building } \\
\text { configuration }\end{array}$ & $\begin{array}{l}\text { Geometrical } \\
\text { parameter }\end{array}$ & Median value [m] & Logarithmic Std. Dev. [-] & Min [m] & Max [m] \\
\hline Type $1^{\text {(a) }}$ & Beam span & 14.9 & 0.3 & 8 & 30 \\
& Frame spacing & 6.8 & 0.28 & 8 & 10 \\
& Column height & 6.5 & 0.25 & 4 & 12 \\
\hline Building & Geometrical & & & & \\
configuration & parameter & Median value [m] & Std. Dev. [m] & 8 & Max [m] \\
\hline Type $2^{\text {(b) }}$ & Beam span & 8.7 & 2.1 & 10 & 10 \\
& Frame spacing & 16.5 & 3.7 & 4 & 11 \\
& Column height & 6.5 & 1.3 & 45 \\
\hline
\end{tabular}

${ }^{(a)}$ Lognormal distribution; ${ }^{(b)}$ Normal distribution

The construction date may represent an important factor for the analysis the seismic behaviour of the precast buildings struck by the Emilia earthquakes, because of the changes in construction practice and technology occurred over time. However, most of the territory struck by the earthquakes was not considered a seismic area by design codes until October 2005. As a consequence, most of the partial and full collapses were caused by the usage, both in Type 1 and Type 2 buildings, of friction-based slab-beam and beam-column connections.

\subsection{Definition of the building stock}

In the present paper, the total number of industrial buildings located within the area of interest was estimated using cadastral data. In Italy, the cadastre has the role of public registry of real estates and land properties and is established mainly for fiscal purposes.

The elementary urban real estate unit is defined as the smallest real estate asset with functional autonomy and ability to produce income. The Italian cadastre is divided into categories related to the activities undergoing in real estate units. In the present study, the building stock was defined with 
reference to two specific cadastral categories, labelled D/1 and D/7, and corresponding to "factories" and "buildings hosting a specific industrial activity", respectively. Since in some cases one building can be constituted by more than one real estate unit, the actual number of industrial buildings forming the reference population does not correspond to the number of cadastral units included into categories $\mathrm{D} / 1$ and $\mathrm{D} / 7$. A detailed analysis was then performed and the number of actual (independent) buildings, evaluated using aerial photography and some field-surveys, was compared with the number of cadastral units for 18 representative municipalities selected among the total of 35 in the area of interest. This analysis showed that the ratio of actual buildings over cadastral units is, on average, about 0.52 . The total size of the building stock (number of independent industrial buildings) for the 17 municipalities not analysed in detail was then estimated by multiplying the total number of real estate units obtained from the cadastral register [17] by 0.52 . It is worth noticing that the procedure adopted possibly overestimated the actual number of prefabricated industrial RC buildings because the cadastre might classify in categories $\mathrm{D} / 1$ and $\mathrm{D} / 7$ also cast-in-place concrete and masonry structures which might not have been identified from aerial photography and field surveys.

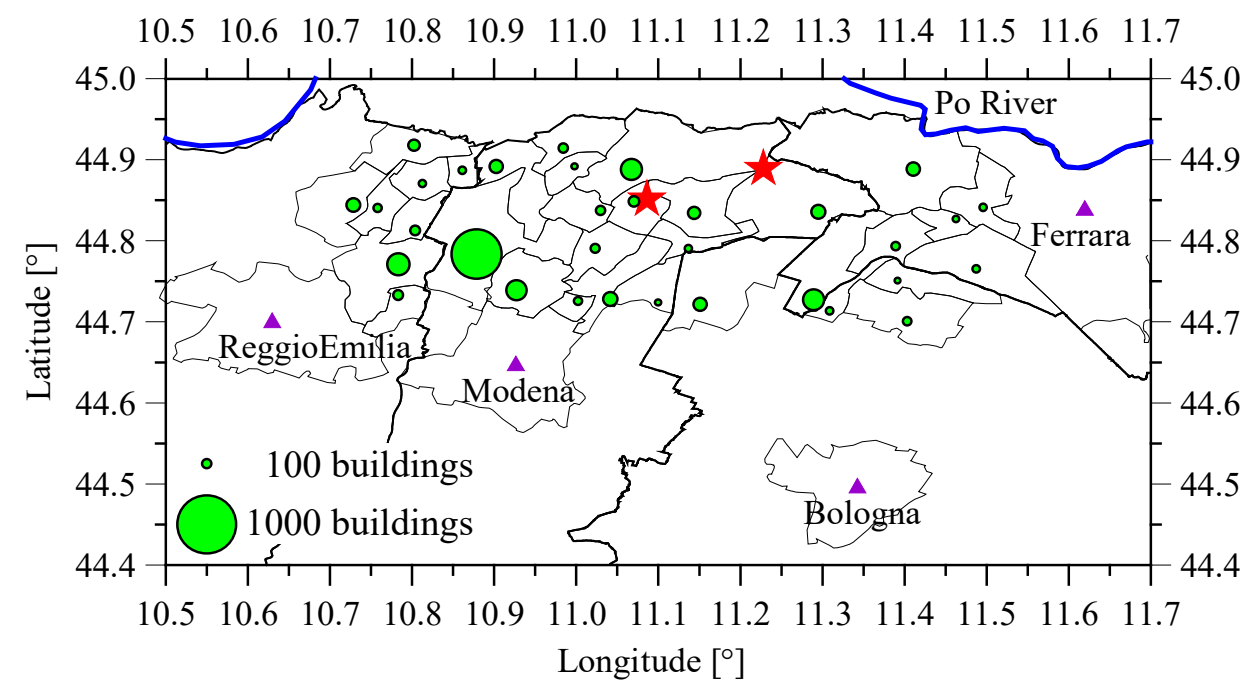

Fig. 1. Map of the territory hit by 2012 Emilia earthquake reporting the distribution of the industrial building stock (green circle data points) and the epicentres of the two mainshocks (red stars).

The distribution of the building stock within the region of interest, estimated as described above, is reported in the map of Fig. 1, where green circles are located on the administrative centres of the municipal territories. The maximum concentration of industrial buildings is observed in the Carpi district.

\subsection{The damage database}

The peculiar seismic behaviour of precast RC buildings, and in particular the vulnerability of the connections between structural elements, made the standard survey-forms used in Italy for postearthquake damage and safety assessment [30] not suitable to collect data for this structural typology. In the present paper, given the absence of information from a specific fast survey procedure, damage data were collected form reports prepared by structural engineers, obtaining more detailed and accurate damage estimates than from fast surveys. These reports were prepared by professional engineers, representing building owners, as partial requirement for obtaining regional funds for either reconstruction or retrofit, in accordance with Regional Decree 57/2012 [31]. These reports were validated by a public in-house company in charge of assessing the coherence of public funding with the interventions planned in design. It is worth noticing that funding was available also for retrofitting non-damaged buildings, and that retrofitting of industrial buildings with structural deficiencies (e.g. lack of mechanical connections between elements) was mandatory. Nonetheless some building owners decided to not apply for funding as per Regional Decree 57/2012 for three main reasons: i) buildings were not occupied; ii) they preferred to apply for national funds for building refurbishment, which were convenient in some cases; iii) they had private insurances covering seismic damage. 
Table 2. Damage levels considered in the study.

\begin{tabular}{|c|c|c|c|}
\hline Damage grade & \multicolumn{2}{|c|}{ Type of damage } & Definition \\
\hline & $\begin{array}{l}\text { Non- } \\
\text { structural }\end{array}$ & Structural & \\
\hline $\mathrm{D}_{0}$ (No damage) & - & - & No damage \\
\hline $\begin{array}{l}\mathrm{D}_{1} \\
\text { (Slight damage) }\end{array}$ & Slight & - & $\begin{array}{l}\text { Local or distributed damage to up to } 20 \% \text { of horizontal and/or } \\
\text { vertical partitions without collapses }\end{array}$ \\
\hline $\begin{array}{l}\mathrm{D}_{2} \\
\text { (Moderate damage) }\end{array}$ & Moderate & Slight & $\begin{array}{l}\text { Local or distributed damage to more than } 20 \% \text { of horizontal } \\
\text { and/or vertical partitions without collapses }\end{array}$ \\
\hline $\begin{array}{l}\mathrm{D}_{3} \\
\text { (Severe damage) }\end{array}$ & Heavy & Moderate & $\begin{array}{l}\text { Severe damage to up to } 15 \% \text { of horizontal and/or vertical } \\
\text { covering surfaces with collapses; or at least one column with } \\
\text { permanent drift larger than } 2 \%\end{array}$ \\
\hline $\begin{array}{l}\mathrm{D}_{4} \\
\text { (Heavy damage) }\end{array}$ & Very heavy & Heavy & $\begin{array}{l}\text { Severe damage to up to } 30 \% \text { of horizontal and/or vertical } \\
\text { covering surfaces with collapses; or to up to } 20 \% \text { of columns, } \\
\text { with permanent drift larger than } 2 \% \text {, or plastic hinge at the base } \\
\text { section }\end{array}$ \\
\hline $\begin{array}{l}D_{5} \\
\text { (Collapse) }\end{array}$ & Total or par & collapse & $\begin{array}{l}\text { Collapses of more than } 30 \% \text { of horizontal and/or vertical } \\
\text { covering surfaces; or damage to more than } 20 \% \text { of columns }\end{array}$ \\
\hline
\end{tabular}

Accurate descriptions of the typical damage occurred to industrial buildings and its possible causes are discussed in [26-28]. In the present study, the damage data were classified according to the six level damage scale reported in Table 3 (see [32]), adapted from the provisions of Regional Decree 57/2012 [31], and substantially coincident with the European Macroseismic Scale [33]. Examples of recurrent modes of damage, observed in precast buildings struck by the Emilia seismic sequence, are reported in Fig. 2. In particular, the formation of plastic hinges at the base of columns (Fig. 2a) may be related to damage levels $D_{4}$ or $D_{5}$ depending on the number of damaged columns. The loss of support of roof slabs (Fig. 2b) and collapse of RC cladding panels (Fig. 2c) may correspond to damage levels $D_{3}, D_{4}$ or $D_{5}$ depending on the extent of the collapsed surfaces (see Table $3)$, i.e., the number of cladding panels involved.
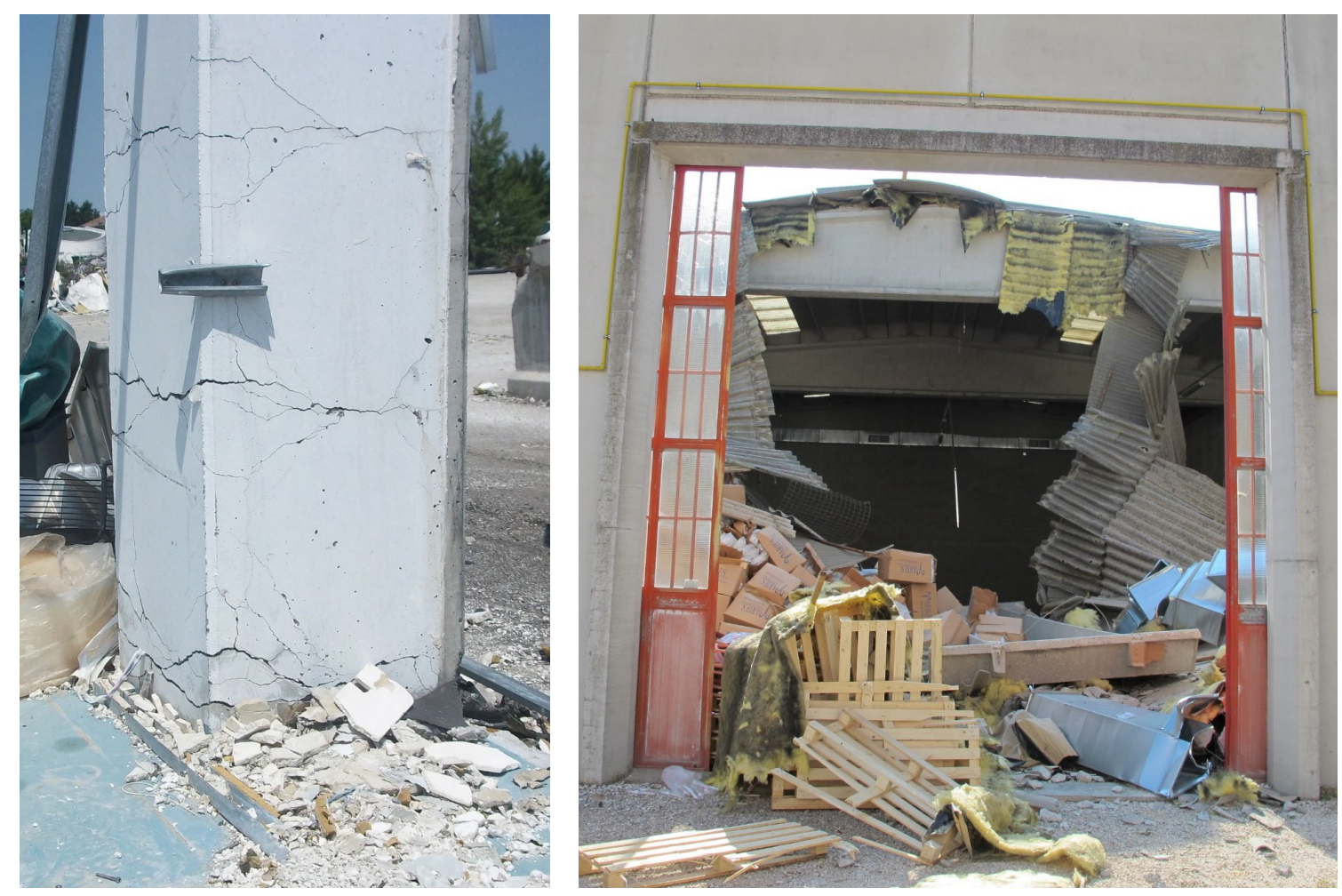


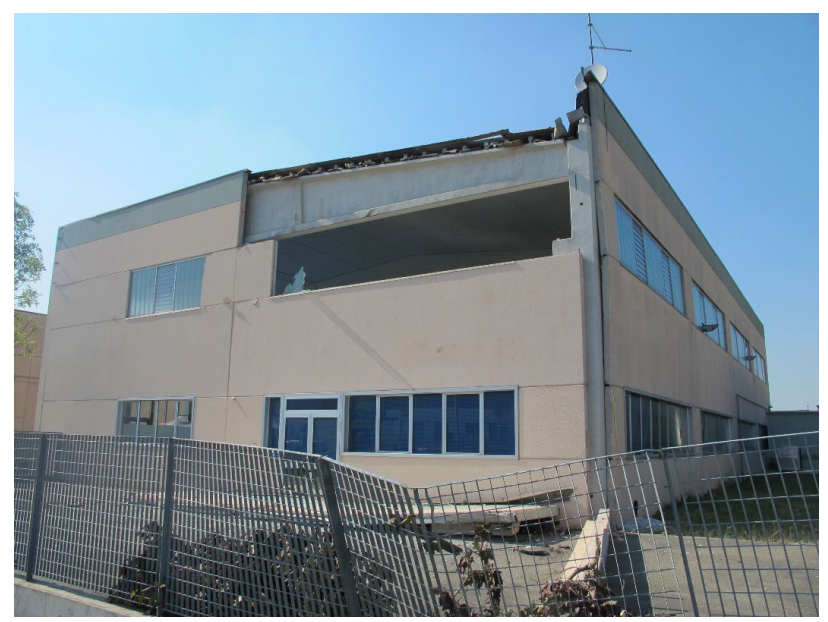

Fig. 2. Typical damage observed in precast buildings struck by the Emilia earthquakes: (a) plastic hinge at the base of a column; (b) loss-of-support of a simply-supported roof slab from main girders; and (c) out-of-plane overturning of RC cladding panels.

The total number of precast buildings included into the damage database gathered for the present study is 1890 . The number of buildings belonging to each damage level is reported in Table 3 . The normalized cumulative number of buildings investigated, defined as the cumulative number of buildings divided by the total number of buildings (i.e. 1890), is plotted, in Fig. 3 (curve labelled $D \geq D_{0}$ ), against the epicentral distance, defined as the distance of each building from the nearest epicentre, between those of the two mainshocks. For 1341 buildings, this distance is associated to the second mainshock (29 May).

Table 3. Number of buildings analysed for each damage level.

\begin{tabular}{llllllll}
\hline Damage level & $D_{0}$ & $D_{1}$ & $D_{2}$ & $D_{3}$ & $D_{4}$ & $D_{5}$ & $D_{1}+\ldots+D_{5}$ \\
\hline No. of buildings in the database & 967 & 371 & 174 & 105 & 76 & 197 & 1890 \\
\hline
\end{tabular}

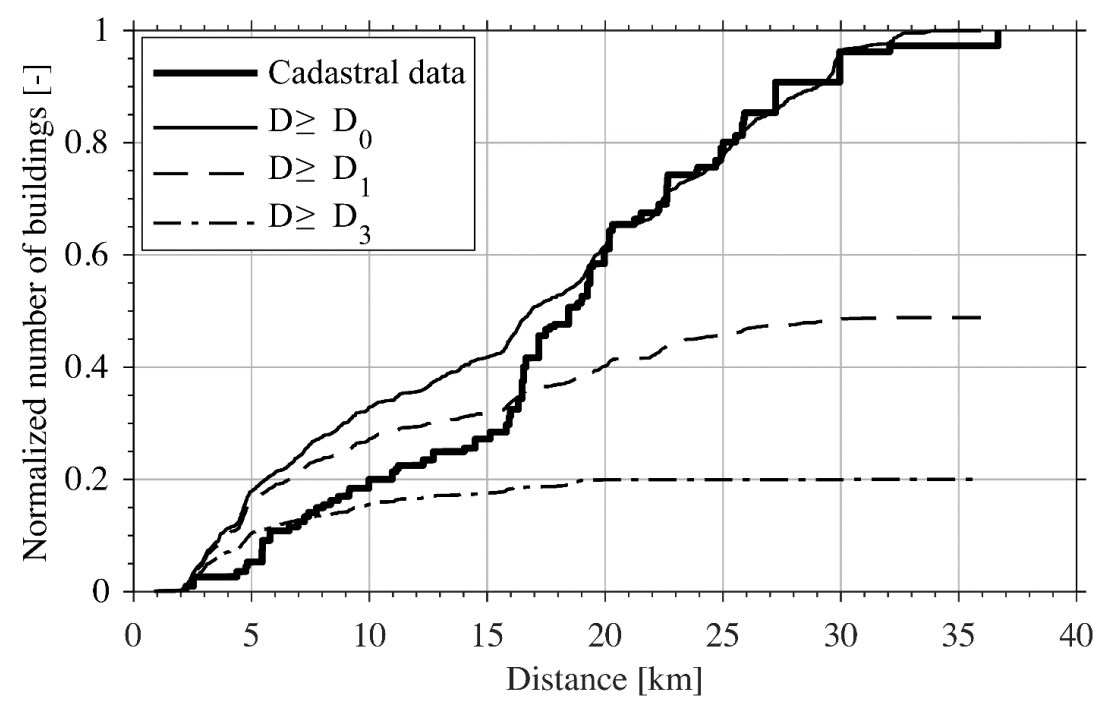

Fig. 3. Normalized cumulative number of industrial buildings versus distance from the nearest epicentre.

In order to check the level of completeness of the data collected, the normalized cumulated number of buildings, estimated from cadastral data as described in Section 2.2, is also reported in the same figure (curve labelled "cadastral data"). This curve is normalized to the total number of buildings estimated from cadastral data. The positions of these buildings were defined based on the main industrial areas identified by aerial photography, in particular all the buildings in each industrial 
area were assumed at its centre. The shapes of the curves corresponding to the database and to the cadastral estimate are in good agreement. The sudden increase in the building density between distances of $16 \mathrm{~km}$ to $20 \mathrm{~km}$ corresponds to a series of large industrial zones in Carpi, in the Modena district. That area is peculiar in the region. In fact, it contains mainly large textile manufactories, a production sector which, in the Emilia region, was severely affected by an economic crisis started in 2009. For this reason, many buildings in the Carpi area were not-in use at the time of the earthquakes and their owners did not submit reports to the authority to obtain funds; therefore their damage was not classified. The number of buildings in the database represents about $30 \%$ of the building stock estimated form cadastral units. It is worth noticing that the building distribution in the area is not uniform, otherwise the curve representing the cumulated distribution of buildings would be quadratic in terms of epicentral distance [32]. Finally, Fig. 3 also shows the normalized cumulative number of buildings against the distance to the nearest epicentre for $D \geq D_{1}$ (i.e., the total number of damaged buildings in the database), and $D \geq D_{3}$ (the number of buildings with severe damages up to partial or total collapse). Note that most of the buildings with $D \geq D_{3}$ are located within $15-20 \mathrm{~km}$ from the nearest epicentre. For epicentral distances shorter than $10 \mathrm{~km}$, a clear predominance of damaged buildings is observed.

\section{DAMAGE DISTRIBUTION VS. GROUND-MOTION INTENSITY}

Over the largest part of the territory, the maximum ground-motion intensity was recorded during the two mainshocks, occurred on 20 May $\left(\mathrm{M}_{\mathrm{w}}=6.1\right)$ and 29 May $\left(\mathrm{M}_{\mathrm{w}}=6.0\right), 2012$ [34]. Therefore, the measures of ground-motion intensity adopted in the present study refer to these two seismic events only.

\subsection{Definition of ground-motion intensity}

The ground-motion intensity at the different building locations was obtained from the official shakemap data published online by Istituto Nazionale di Geofisica e Vulcanologia (INGV) [35]. These data provide information on the intensity of ground-shaking in terms of either PGA, PGV, and Pseudo-Spectral Accelerations (PSA) at $0.3 \mathrm{~s}, 1.0 \mathrm{~s}$ and $3.0 \mathrm{~s}$, combining actual ground-motion recordings and predictions from attenuation relationships. These shakemaps are computed assuming that the ground-motion intensity at each location is lognormally distributed. For the fragility assessment presented in the following, after analysing the ground-motion accelerograms from the recording stations and the site-to-site variability of different possible ground-motion intensity measures, the maximum horizontal PGA was chosen as measure of ground-motion intensity. In fact, spectral accelerations at different natural periods were characterized by a very large variability.

Figs. 4a-b show the shakemaps for the median value of the horizontal PGA referred to the 20 May and 29 May earthquakes, respectively. Figs. 4c-d show maps of the standard deviation of the natural logarithm of PGA for the two events. The uncertainty on the shakemaps for the two earthquakes is very different. In fact, many temporary ground-motion recording stations were installed after the first mainshock, and therefore the shakemaps for the subsequent shocks (and in particular for the earthquake occurred on 29 May, 2012) are more accurate. The logarithmic standard deviation of PGA will be used in the derivation of the fragility curves presented in Section 5.4. For a discussion on the level of approximation of the official shakemaps for the Emilia earthquakes see [36, 37]. 

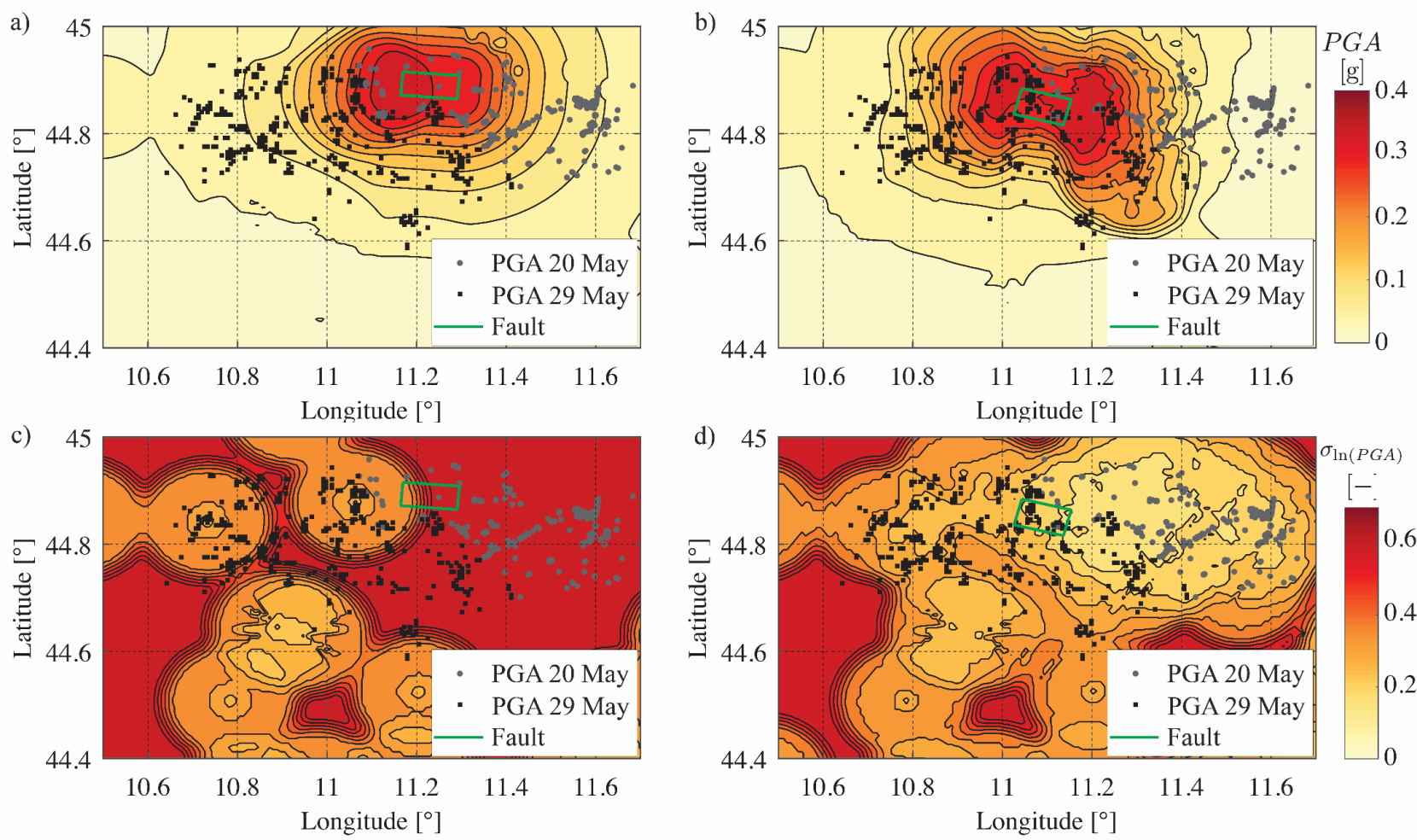

Fig. 4. Shakemaps for (a-b) the median value of the horizontal PGA, and (c-d) for its logarithmic standard deviation (SD), for (a, c) the 20 May and (b, d) 29 May earthquakes. Grey dots and black squares indicate the locations of the buildings in database associated to the PGA of 20 May and 29

May, respectively.

Since the strong-motion parameters provided by INGV are referred to a dense spatial grid with nodes every $1 \mathrm{~km}$, according to the rule suggested by the Italian Building Code [38] the PGA at each building location was computed as the weighted mean value of the PGAs at the four closest grid nodes, with the $i$-th weight being the reciprocal of the distance between the location and the $i$-th node.

For each building, the value of the ground-motion intensity considered was the maximum between those related to the two mainshocks of 20 and 29 May. Grey dots and black squares in Fig. 4 indicate the locations of the buildings in the database associated to the 20 May and 29 May PGA, respectively. Note that for most of the buildings associated to the 20 May ground-motion the logarithmic standard deviation (Fig. 4c-d), is as large as 0.6 , which corresponds to the total standard deviation of the attenuation relationships used to compute the shakemaps.

Considering, as ground-motion intensity, the maximum PGA generated by the two mainshocks, corresponds to assuming that the damage produced by the two seismic events was not correlated. This assumption is supported by the outcomes of field surveys [26, 32]. In fact, the prefabricated RC structures in the area were typically characterized by extremely fragile failure modes since they did not have any structural redundancy and featured friction-based connections between elements (see Section 2.1). Even when mechanical connectors were present, their strength was insufficient because they were not designed for seismic actions, but only to facilitate the assembly of prefabricated structural members during construction [26]. Therefore, these structures had no redistribution capacity. This behaviour was highlighted by some field surveys carried out after both the mainshocks, especially in the Mirandola area. This industrial area is particularly interesting because, during the two events, it experienced similar PGA values (recorded by a permanent accelerometric station), i.e. $258 \mathrm{~cm} / \mathrm{s}^{2}$ and $288 \mathrm{~cm} / \mathrm{s}^{2}$, respectively. In spite of the similar PGA values, there were many cases of buildings totally undamaged after 20 May which collapsed on 29 May because of failures in frictionbased connections, the most common of which were the unseating of either beams from columns or roofing elements from beams [26]. Of course, near-source effects might have contributed to the collapses occurred on May 29 [26]. 


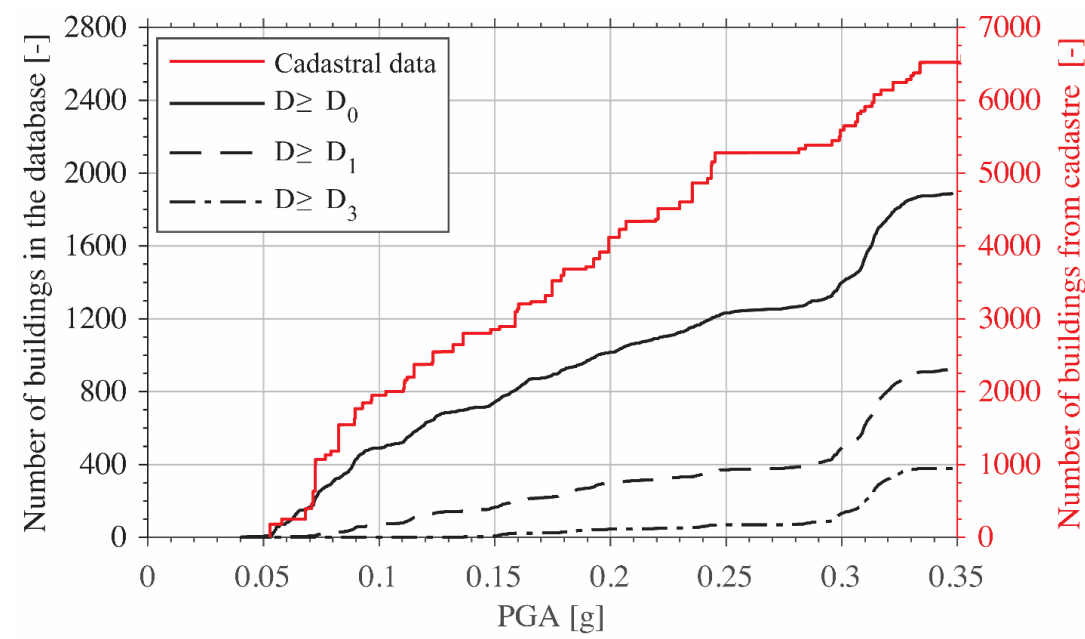

Fig. 5. Cumulative number of industrial buildings, in the survey area, which experienced a peak ground acceleration less or equal to the PGA values reported in abscissa: building stock from cadastral data (right axis), all buildings in the database $\left(D \geq D_{0}\right)$, buildings with damage level $D \geq$ $D_{1}$, and $D \geq D_{3}$.

\subsection{Damage distribution versus PGA}

The cumulative number of buildings with damage level $D$ greater than or equal to either $D_{0}, D_{1}$, or $D_{3}$ is reported in Fig. 5, together with the cumulative number of buildings estimated from cadastral data (see Sections 2.2 and 2.3), versus the maximum horizontal PGA.

For PGA $\leq 0.28 \mathrm{~g}$, there are 1267,385 , and 72 buildings with damage $D \geq D_{0}, D \geq D_{1}$, and $D \geq D_{3}$, respectively. For high accelerations the curves feature a sudden step. Since this peculiar shape can be observed also for $D \geq D_{0}$ (i.e. the whole database) and for the building stock estimated from cadastral units, the step must be a consequence of the non-uniform distribution of buildings (see Section 2.3) and of the spatial distribution of PGA. In fact, the curve derived from cadastral data is completely independent from damage and unaffected by the procedure used to collect data. On the other hand, it is worth noticing that the relative increment in the number of damaged buildings before and after the step is much higher for $D \geq D_{3}(+323 \%)$ than for $D \geq D_{1}(+122 \%)$ and $D \geq D_{0}(+45 \%)$. Therefore, these different percentages might suggest that a portion of the sudden increment in the number of buildings with at least severe damage could be related to the activation of specific damage modes. Finally, the similitude of the shapes of the curves for $D \geq D_{0}$ and for the building stock estimated from cadastral data is an indicator of the soundness of the data collection procedure.

\section{DAMAGE ANALYSIS AND FRAGILITY}

\subsection{Damage data}

In order to analyse the fragility of the buildings in the database, the 1890 damage data were categorized into the damage matrix reported in Table 4 [39], considering seven intervals for the PGA (column $I_{P G A, i}$ ). The criteria used to define these intervals will be discussed at the end of Section 4.2 being related to fragility estimation. Table 4 provides, for each PGA interval, the number of buildings associated to each damage level. For example, among the 257 buildings that experienced a PGA between $0.297 g$ and $0.313 g, 35$ were undamaged $\left(D=D_{0}\right)$, and $44,52,35,25$, and 35 buildings were classified in damage levels $D_{1}, D_{2}, D_{3}, D_{4}$, and $D_{5}$, respectively.

Table 4. Damage matrix for all buildings collected in the database: number of buildings for each damage level vs. intervals of PGA.

\begin{tabular}{l|rrrrrr}
\hline$I_{P G A, i}[\mathrm{~g}]$ & $D=D_{0}$ & $D=D_{1}$ & $D=D_{2}$ & $D=D_{3}$ & $D=D_{4}$ & $D=D_{5}$ \\
\hline$[0.000-0.076[$ & 249 & 21 & 1 & 0 & 1 & 0 \\
{$[0.076-0.112[$} & 205 & 57 & 6 & 0 & 0 & 0 \\
{$[0.112-0.159[$} & 158 & 80 & 10 & 4 & 8 & 10
\end{tabular}




\begin{tabular}{c|rrrrrr}
{$[0.159-0.216[$} & 153 & 74 & 18 & 7 & 3 & 15 \\
{$[0.216-0.297[$} & 133 & 51 & 27 & 19 & 14 & 26 \\
{$[0.297-0.313[$} & 35 & 44 & 52 & 35 & 25 & 66 \\
{$[0.313-0.349]$} & 34 & 44 & 60 & 40 & 25 & 80 \\
\hline Total & 967 & 371 & 174 & 105 & 76 & 197 \\
\hline
\end{tabular}

Table 5. Cumulative damage matrix for all buildings in the database.

\begin{tabular}{l|rrrrrr}
\hline$I_{P G A, i}[\mathrm{~g}]$ & $D \geq D_{0}$ & $D \geq D_{1}$ & $D \geq D_{2}$ & $D \geq D_{3}$ & $D \geq D_{4}$ & $D=D_{5}$ \\
\hline$[0.000-0.076[$ & 272 & 23 & 2 & 1 & 1 & 0 \\
{$[0.076-0.112[$} & 268 & 63 & 6 & 0 & 0 & 0 \\
{$[0.112-0.159[$} & 270 & 112 & 32 & 22 & 18 & 10 \\
{$[0.159-0.216[$} & 270 & 117 & 43 & 25 & 18 & 15 \\
{$[0.216-0.297[$} & 270 & 137 & 86 & 59 & 40 & 26 \\
{$[0.297-0.313[$} & 257 & 222 & 178 & 126 & 91 & 66 \\
{$[0.313-0.349]$} & 283 & 249 & 205 & 145 & 105 & 80 \\
\hline Total & 1890 & 923 & 552 & 378 & 273 & 197 \\
\hline
\end{tabular}

Moreover, from Table 4, the cumulative damage matrix reported in Table 5 was obtained. This table shows the number of buildings which were exposed to a PGA belonging to the interval indicated in the first column, and that were associated to a damage level greater than or equal to $D_{j}$. For instance, 126 of the 257 buildings that experienced a maximum horizontal PGA between $0.297 \mathrm{~g}$ and $0.313 \mathrm{~g}$ had damage levels greater than $D_{3}$. Of course, the column $D \geq D_{0}$ indicates the total number of buildings for each PGA interval.

\subsection{Point estimates of fragility}

Using the cumulative damage matrix, it is possible to obtain a first estimate of the fragility of the buildings. In fact, the probability of observing $n_{i, j}$ buildings with damage $D \geq D_{j}$ in the $i$-th groundmotion intensity interval $I_{\mathrm{PGA}, i}$ can be represented by the following binomial distribution [40]:

$$
\begin{gathered}
P\left(n_{i, j} \text { in } N_{i} \text { with } D \geq D_{j}\right)=\left(\begin{array}{c}
N_{i} \\
n_{i, j}
\end{array}\right) p_{i, j}^{n_{i, j}}\left(1-p_{i, j}\right)^{N_{i}-n_{i, j}} \\
\left(\begin{array}{c}
N_{i} \\
n_{i, j}
\end{array}\right)
\end{gathered}
$$

$\hat{p}_{i, j}=n_{i, j} / N_{i}$

and its variance as:

$\operatorname{vâr}\left(p_{i, j}\right)=\hat{p}_{i, j}\left(1-\hat{p}_{i, j}\right) / N_{i}$

where $^{\wedge}$ indicates estimates. 

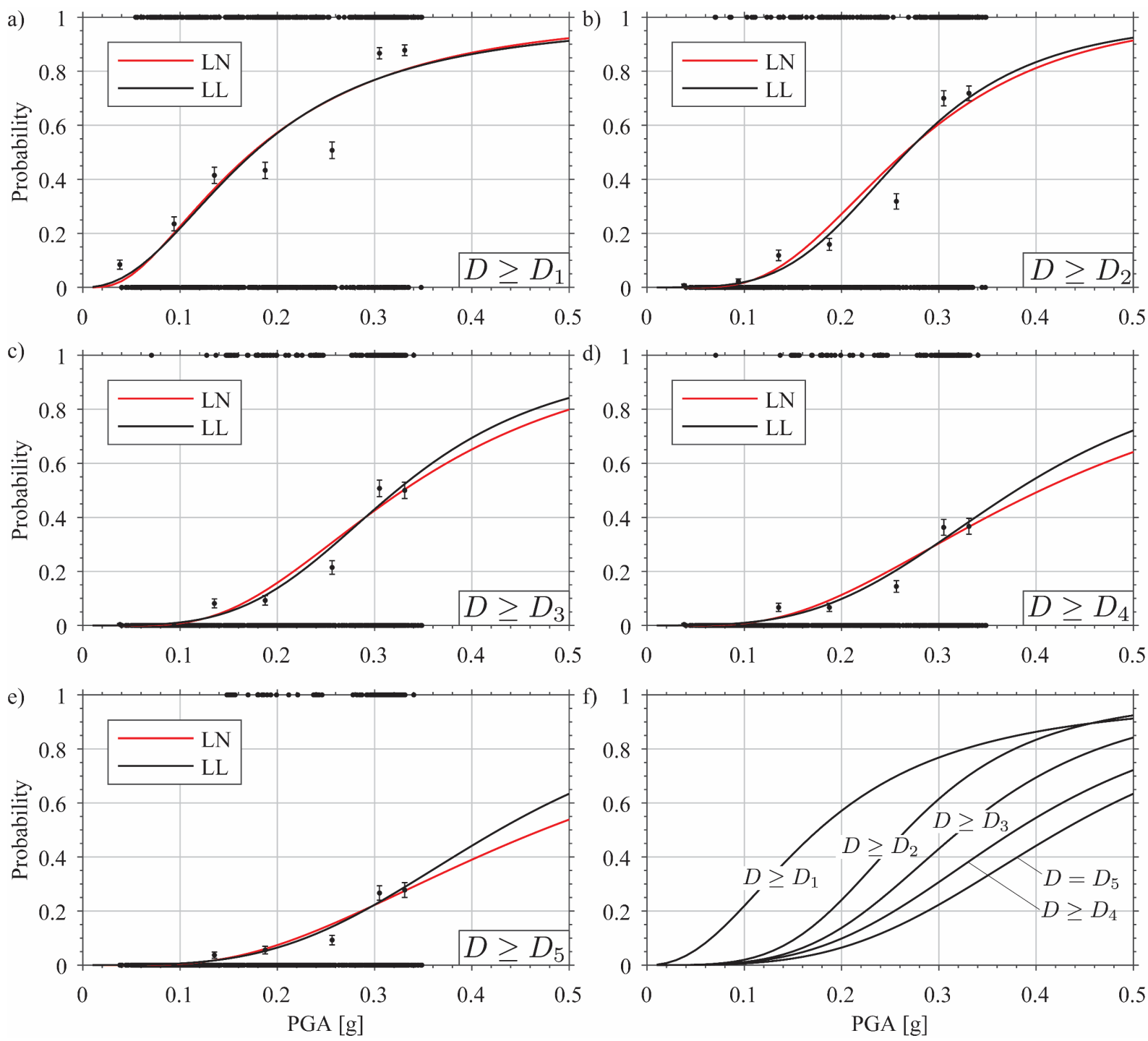

Fig. 6. (a-e) comparison among failure probabilities for damage levels $D_{1}$ to $D_{5}$, point-estimates from damage matrices (black circles), lognormal (LN) and log-logit (LL) parametric fragility curves obtained by maximum likelihood estimation; (f) LL parametric fragility curves for the various damage levels.

Using the data of the damage matrix reported in Table 5 together with Eq. (2), the failure probabilities for $D \geq D_{j}(j=1$ to 4$)$ and $D=D_{5}$ were estimated. These probabilities are given in Table 6 . The central value $\mu_{P G A, i}$ of each interval, defined as the arithmetic mean of the PGA values, is also reported. The damage probabilities in Table 6 are also plotted in Fig. 6 (black circles), together with \pm 1 standard deviation intervals obtained from Eq. (3).

The boundaries of the 7 PGA intervals were selected in order to: 1 ) have a similar number of buildings in each interval (approximately 270) [39], see the column $D \geq D_{0}$ of Table 5 and; ii) obtain, for each damage level, non-decreasing exceedance-probability values for increasing PGAs. It should be noted that the intervals adopted were used only to provide a graphical representation of fragility and do not affect the parametric fragility models discussed in the following. 
Table 6. Estimated failure probability for each damage level.

\begin{tabular}{l|r|rrrrr}
\hline$I_{P G A, i}[\mathrm{~g}]$ & $\mu_{P G A, i}[\mathrm{~g}]$ & $D \geq D_{1}$ & $D \geq D_{2}$ & $D \geq D_{3}$ & $D \geq D_{4}$ & $D=D_{5}$ \\
\hline$[0.000-0.076[$ & 0.04 & 0.08 & 0.01 & 0.00 & 0.00 & 0.00 \\
{$[0.076-0.112[$} & 0.09 & 0.24 & 0.02 & 0.00 & 0.00 & 0.00 \\
{$[0.112-0.159[$} & 0.14 & 0.41 & 0.12 & 0.08 & 0.07 & 0.04 \\
{$[0.159-0.216[$} & 0.19 & 0.43 & 0.16 & 0.09 & 0.07 & 0.06 \\
{$[0.216-0.297[$} & 0.26 & 0.51 & 0.32 & 0.22 & 0.15 & 0.10 \\
{$[0.297-0.313[$} & 0.31 & 0.86 & 0.69 & 0.49 & 0.35 & 0.26 \\
{$[0.313-0.349]$} & 0.33 & 0.88 & 0.72 & 0.51 & 0.37 & 0.28 \\
\hline
\end{tabular}

\section{PARAMETRIC FRAGILITY CURVES}

\subsection{General approach}

Parametric fragility curves were fitted starting from the damage data described above. Various models and regression procedures have been proposed in the literature to obtain fragility curves from observational data, as described in the comprehensive review recently published by Lallemant et al. [40]. In the present work, different models were considered, adopting a Bayesian approach in order to estimate their parameters [41].

$$
P_{f}(I M)=f(I M ; \boldsymbol{\Theta}) \text {. }
$$

In Bayesian statistics the current knowledge of $\boldsymbol{\Theta}$ is defined by a joint density $f(\boldsymbol{\Theta})$ function, referred to as priori distribution. Once a vector $y$ of observed data is available, the Bayes theorem can be used to update the knowledge of the parameters, so obtaining a posterior distribution:

$$
\begin{gathered}
f(\boldsymbol{\Theta} \mid \boldsymbol{y})=\frac{P(\boldsymbol{y} \mid \boldsymbol{\Theta}) f(\boldsymbol{\Theta})}{P(\boldsymbol{y})}=\frac{P(\boldsymbol{y} \mid \boldsymbol{\Theta}) f(\boldsymbol{\Theta})}{\int P(\boldsymbol{y} \mid \boldsymbol{\Theta}) f(\boldsymbol{\Theta}) d \boldsymbol{\Theta}} \\
P(\boldsymbol{y} \mid \boldsymbol{\Theta})
\end{gathered}
$$

[41].

\subsection{Fragility curves based on individual damage levels}

The present Section describes the procedure adopted for fitting parametric fragility models for the general damage exceedance condition $D \geq D_{j}$. To this aim, the observed damage data is first transformed, for each damage level $D_{j}$, into a binary variable $y_{i, j}$ which is equal to 1 if, in the $i$-th building, damage is not less than $D_{j}$ and 0 otherwise. Assuming that the damage data $y_{i, j}$ are independent and identically distributed (i.i.d.) the likelihood function $L_{j}$ for the general damage level $D_{j}$ can be defined as $[40,42,43]$ :

$$
L_{j}=P\left(\boldsymbol{y}_{j} \mid \boldsymbol{\Theta}_{j}\right)=\prod_{i=1}^{N}\left(1-p_{i, j}\left(I M_{i} ; \boldsymbol{\Theta}_{j}\right)\right)^{\left(1-y_{i, j}\right)} p_{i, j}\left(I M_{i} ; \boldsymbol{\Theta}_{j}\right)^{y_{i, j}}
$$

where $N$ indicates the total number of buildings

$$
\Theta_{j}
$$


$\boldsymbol{y}_{j}=\left\lfloor y_{i, j}, \ldots, y_{N, j}\right\rfloor$. Eq. 6 corresponds to assuming that each binary damage observation, $y_{i, j}$, follows a Bernoulli distribution, $B$, with probability $p_{i, j}$ :

$$
y_{i, j} \sim B\left(1, p_{i, j}\left(I M, \boldsymbol{\Theta}_{j}\right)\right) \text {. }
$$

It is worth noticing that the whole dataset is used for evaluating the likelihood function (6) for each damage level $D_{j}$.

In the present work, two different models were considered for expressing $p_{i, j}$ as a function of groundmotion intensity: a lognormal (LN) and a log-logit (LL) model. In the first case the failure probability $p_{i, j}$ is written as

$$
\begin{aligned}
& p_{i, j}=\Phi\left(\frac{\ln \left(I M_{i}\right)-\mu_{j}}{\sigma_{j}}\right) \\
& \qquad(.) \quad \\
& \boldsymbol{\Theta}_{j}=\left[\mu_{j}, \sigma_{j} .\right. \\
& \operatorname{logit}\left(p_{i, j}\right)=\beta_{0, j}+\beta_{1, j} \ln \left(I M_{i}\right), \\
& \qquad \boldsymbol{\Theta}_{j}=\left[\beta_{0, j}, \beta_{1, j}\right]
\end{aligned}
$$

Bayesian regression (see Section 5.1) was carried out using the software R and JAGS [44, 45] in order to estimate the parameters of the models. Convergence of the MCMC chains was checked by computing the potential scale reduction factor [41]. Three MCMC chains were used. Uninformative distributions were adopted as priori distributions of the model parameters. The two different models, i.e. LN and LL, were compared using the Deviance Information Criterion (DIC), which is preferable than other criteria as AIC and BIC when using MCMC Bayesian regression [41]. The DIC is computed based on the deviance of a model and its number of parameters and, given the same goodness of fit to a dataset, will favour models with less parameters [41].

Fig. 6 shows the fragility curves obtained using the LN and the LL models. Black dots at the top and bottom of each panel represent the binary damage data, $y_{j}$, used for fitting the models for each damage state $D_{j}$. Table 7 lists the mean values (used as estimates of the parameters) and the standard deviation of the posterior distribution for the two parameters of the LL model. For all the damage states considered the DIC indicated the LL model as preferable, even if by a low margin.

Note that the curve for $D \geq D_{1}$ slightly overlaps the curve for $D \geq D_{2}$ starting from PGA values larger than $0.45 \mathrm{~g}$, which is clearly unjustifiable from a theoretical point of view. It is worth noticing that the dataset used has a maximum PGA value of $0.35 \mathrm{~g}$ and, obviously, extrapolations of the fragility curves are more uncertain. A possible solution to overcome this issue is using statistical models that force ordinality of the damage states [40]. This approach will be discussed in the following. 
Table 7. Mean value (E) and standard deviation (SD) of the posterior distribution of the parameters of the log-logistic models (LL) for the different damage states.

\begin{tabular}{lrrrrr}
\hline & $D \geq D_{1}$ & $D \geq D_{2}$ & $D \geq D_{3}$ & $D \geq D_{4}$ & $D=D_{5}$ \\
\hline $\mathrm{E}\left[\beta_{0}\right][-]$ & 3.902 & 5.268 & 4.329 & 3.360 & 3.001 \\
$\mathrm{SD}\left[\beta_{0}\right][-]$ & 0.192 & 0.301 & 0.344 & 0.371 & 0.445 \\
$\mathrm{E}\left[\beta_{1}\right][1 / \ln (g)]$ & 2.247 & 3.987 & 3.839 & 3.467 & 3.527 \\
$\mathrm{SD}\left[\beta_{1}\right][1 / \ln (g)]$ & 0.108 & 0.214 & 0.258 & 0.281 & 0.344 \\
\hline
\end{tabular}

\subsection{Fragility curves using ordinal models}

In the present section, an ordinal log-logistic (OLL) model is presented with the aim of avoiding overlapping fragility curves. In particular, a link GLM (Generalised Linear Model) was used [46]. Alternative approaches are presented in Agresti [47]. In the model adopted in this section all the damage states are considered toghether and a single likelihood function is defined. In this section, the damage for the $i$-th building is defined in terms of an ordinal damage variable $y_{i}$, which can assume integer values from 0 to 5 , corresponding to damage levels ranging from $D_{0}$ to $D_{5}$, respectively.

$$
y^{*}
$$

$$
y_{i}^{*}=\ln \left(I M_{i}\right) \beta+\epsilon_{i}, \quad \epsilon \sim \operatorname{Logistic}(0, s), \quad i=1, \ldots, N,
$$

where $\beta$ is an unknown regression parameter, $\varepsilon$ is a logistically distributed random variable with 0 mean and scale parameter $s$. Using a normal distribution for $\varepsilon$ would generate a cumulative probit model. In the present work, a proportional odds model was assumed, i.e. the $\beta$ parameter value does not depend on the damage level [47

$$
y_{i}^{*}
$$

Table 2), using the following scheme:

$$
\begin{aligned}
& y_{i}^{*} \leq \tau_{0} \Rightarrow y_{i}=0 \\
& \tau_{j-1}<y_{i}^{*} \leq \tau_{j} \Rightarrow y_{i}=j, \quad 1 \leq j \leq 4 \\
& y_{i}=5 \Leftrightarrow y_{i}^{*}>\tau_{4}
\end{aligned}
$$

the different damage levels can be computed as:

$$
\tau_{0}<\tau_{1}<\tau_{2}<\tau_{3}<\tau_{4} \text { The probability of observing }
$$

$$
\begin{aligned}
& P\left[y_{i}=0\right]=P\left[y_{i}^{*} \leq \tau_{0}\right] \\
& P\left[y_{i}=j\right]=P\left[\tau_{j-1}<y_{i}^{*} \leq \tau_{j}\right], \quad 1 \leq j \leq 4 \\
& P\left[y_{i}=5\right]=P\left[y_{i}^{*}>\tau_{4}\right]
\end{aligned}
$$

which can be easily evaluated using the cumulative logistic distribution function as illustrated by Fig. 7

$\delta_{i, j}$

$$
L=\prod_{i=1}^{N} \prod_{j=0}^{5} P\left[y_{i}=j\right]^{\delta_{i, j}}
$$

The parameters of the so defined model are unidentifiable. In fact, any change in the scale parameter $s$ in Eq 10 can be balanced by changes in $\tau$ and $\beta$. Therefore, this model requires a set of normalization constraints. In the present work, the scale parameter $s$ was set to 1 [46]. For the same reason, no 
$\boldsymbol{\Theta}=\left|\beta, \tau_{0}, \tau_{1}, \tau_{2}, \tau_{3}, \tau_{4}\right|$

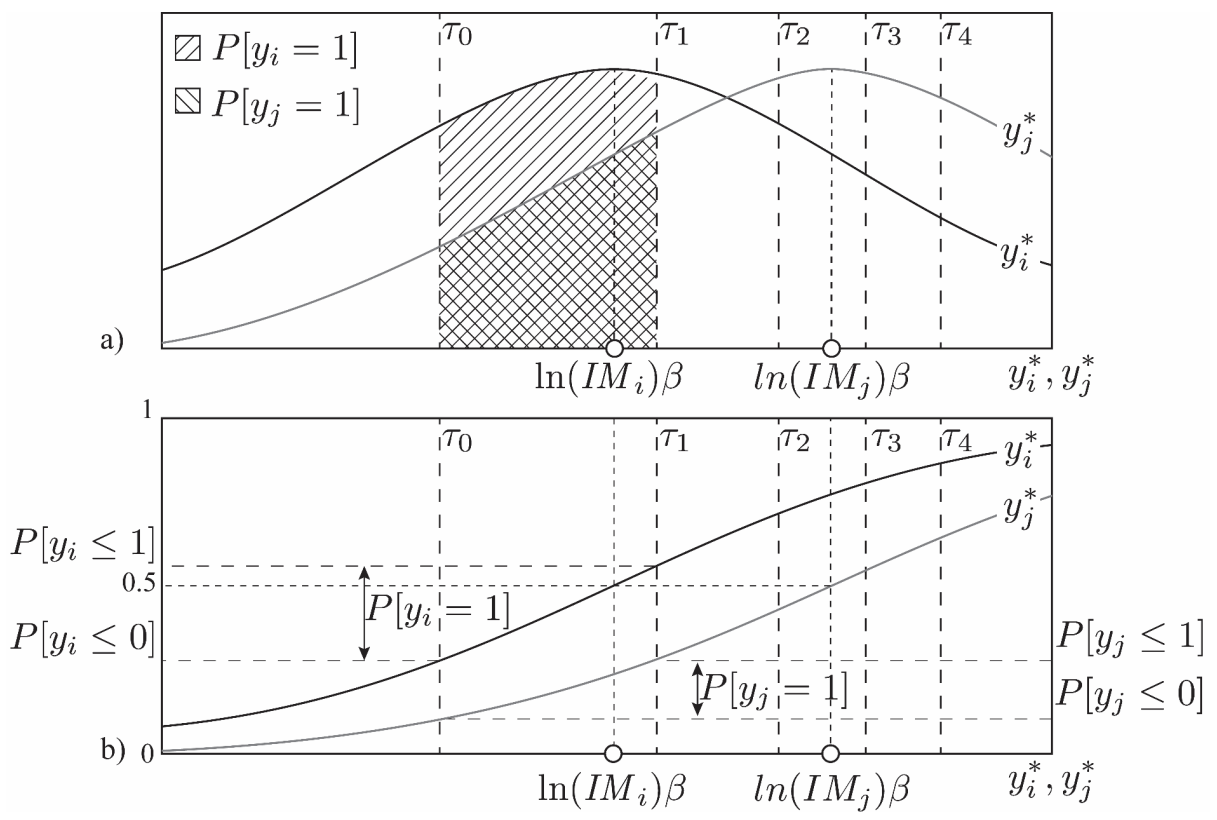

Fig. 7. (a) PDF and (b) CDF for $y_{i}^{*} \mid I M_{i}, \beta$ and $y_{j}^{*} \mid I M_{j}, \beta$, with $I M_{p}>I M_{i}$ and $\beta>0$.

$$
y_{i}^{*} \quad y_{j}^{*}
$$

As suggested in $[46$

$\beta \quad \tau_{0}, \ldots, \tau_{4}$

Table 8.

Considering the linear structure of the regression model in Eq. (10), associated to a non-negative value of the estimate for the $\beta$ parameter, and that cumulative distribution functions are nondecreasing, it is evident that this model will lead to non-overlapping fragility curves.

Table 8. Mean value (E) and standard deviation (SD) of the posterior distribution of the parameters of the ordinal log-logistic models with (OLL-R) and without (OLL) ground-motion uncertainty.

\begin{tabular}{lrrrrrr}
\hline Model & $\mathrm{E}[\beta][1 / \ln (g)]$ & $\mathrm{E}\left[\tau_{0}\right][-]$ & $\mathrm{E}\left[\tau_{1}\right][-]$ & $\mathrm{E}\left[\tau_{2}\right][-]$ & $\mathrm{E}\left[\tau_{3}\right][-]$ & $\mathrm{E}\left[\tau_{4}\right][-]$ \\
\hline OLL & 2.554 & -4.508 & -3.299 & -2.616 & -2.136 & -1.708 \\
OLL-R & 3.306 & -5.727 & -4.243 & -3.404 & -2.823 & -2.315 \\
\hline & $\mathrm{SD}[\beta][1 / \ln (g)]$ & $\mathrm{SD}\left[\tau_{0}\right][-]$ & $\mathrm{SD}\left[\tau_{1}\right][-]$ & $\mathrm{SD}\left[\tau_{2}\right][-]$ & $\mathrm{SD}\left[\tau_{3}\right][-]$ & $\mathrm{SD}\left[\tau_{4}\right][-]$ \\
\hline OLL & 0.103 & 0.183 & 0.167 & 0.161 & 0.161 & 0.163 \\
OLL-R & 0.187 & 0.318 & 0.276 & 0.255 & 0.245 & 0.239 \\
\hline
\end{tabular}

\subsection{Ground-motion uncertainty}

An important factor to consider in fragility estimation is the uncertainty in ground-motion data. The adopted shakemaps (see Section 3.1) assume that the ground-motion intensity, i.e. PGA in this paper, 
at each site has a lognormal distribution with median value and logarithmic standard deviation as provided in Fig. 4. In other words, the true value of the ground-motion intensity, at the $i$-th building location, is not known and can be written as [48]:

$$
\ln \left(I M_{i}^{\text {true }}\right) \sim \mathcal{N}\left(\ln \left(I M_{i}\right), \sigma_{\ln (I M), i}\right)
$$

$$
\mathcal{N}
$$

logarithmic standard deviation (see Fig. 4c-d). Fig. 8

Fig. 4a-b) and $\sigma_{\ln (I M), i}$ its corresponding

Fig. 4). Vertical bars represent \pm 1 standard deviation intervals on the logarithm of PGA, centred on the median PGA value. In general, the PGAs associated to larger standard deviations are mostly those obtained from the shakemaps for the 20 May earthquake (see red points in Fig. 8 and Fig. 4c). It is worth noticing that for the buildings with damage states $D_{3}$ to $D_{5}$ (Fig. 8d-f) small PGA values systematically feature larger standard deviations than large PGA values.

The error model defined in Eq. (14) is normally referred to as Berkson error model [49]. It differs from traditional covariate error models (e.g. error in variables models) in which one assumes that the measured value of the covariate can be defined as the summation of a true value and a random error term with zero mean [49]). Eq (14) assumes that, on average, the ground-motion prediction is unbiased as suggested by Straub and Der Kiureghian [48]. This assumption is also justified based on the procedure adopted for computing shakemaps [50

$$
I M_{i}^{\text {true }}
$$

MCMC Bayesian regression was carried out according to the procedure and criteria described in the previous sections. The mean values and standard deviations of the posterior distributions of the model parameters are reported in Table 8, and the corresponding fragility curves are plotted in Fig. 9, together with curves obtained from the models discussed in the previous sections. It is worth noticing that the curves obtained considering the uncertainty on PGA (OLL-R) are, in general, steeper than those provided by the OLL model. This result can be explained considering the non-uniform uncertainty of the PGA associated to the damage data (Fig. 8). In fact, as discussed above, low PGA values have larger uncertainties. Therefore, these data are penalized in the regression which will favour points with smaller uncertainties. On the other hand, the standard deviation of the posterior distribution of the OLL-R parameters (see Table 8) is larger than for the OLL model and therefore the confidence on the fragility curve (not plotted here) is reduced.

$$
\beta_{1} \ln \left(I M_{i}\right)^{2}
$$

40]. Furthermore, a direct comparison of the goodness of fit of the ordinal model with those in Section 5.2 is not possible because each of these latter uses the full dataset, which is converted into a binary observation variable that will assume different values for each damage level. The models related to the different damage states are therefore fitted independently and have different likelihoods. The ordinal model, on the other hand, uses the full dataset for defining a single likelihood function to obtain fragilities for all damage states. Given these considerations and the different number of regression parameters - in the LL and LN models 2 parameters per damage level are adopted, while in the OLL models 6 parameters in total - the OLL and OLL-R models obviously provide a worst fit to the data if compared to those Section 5.2, but have the important advantage of providing nonoverlapping fragility functions. 

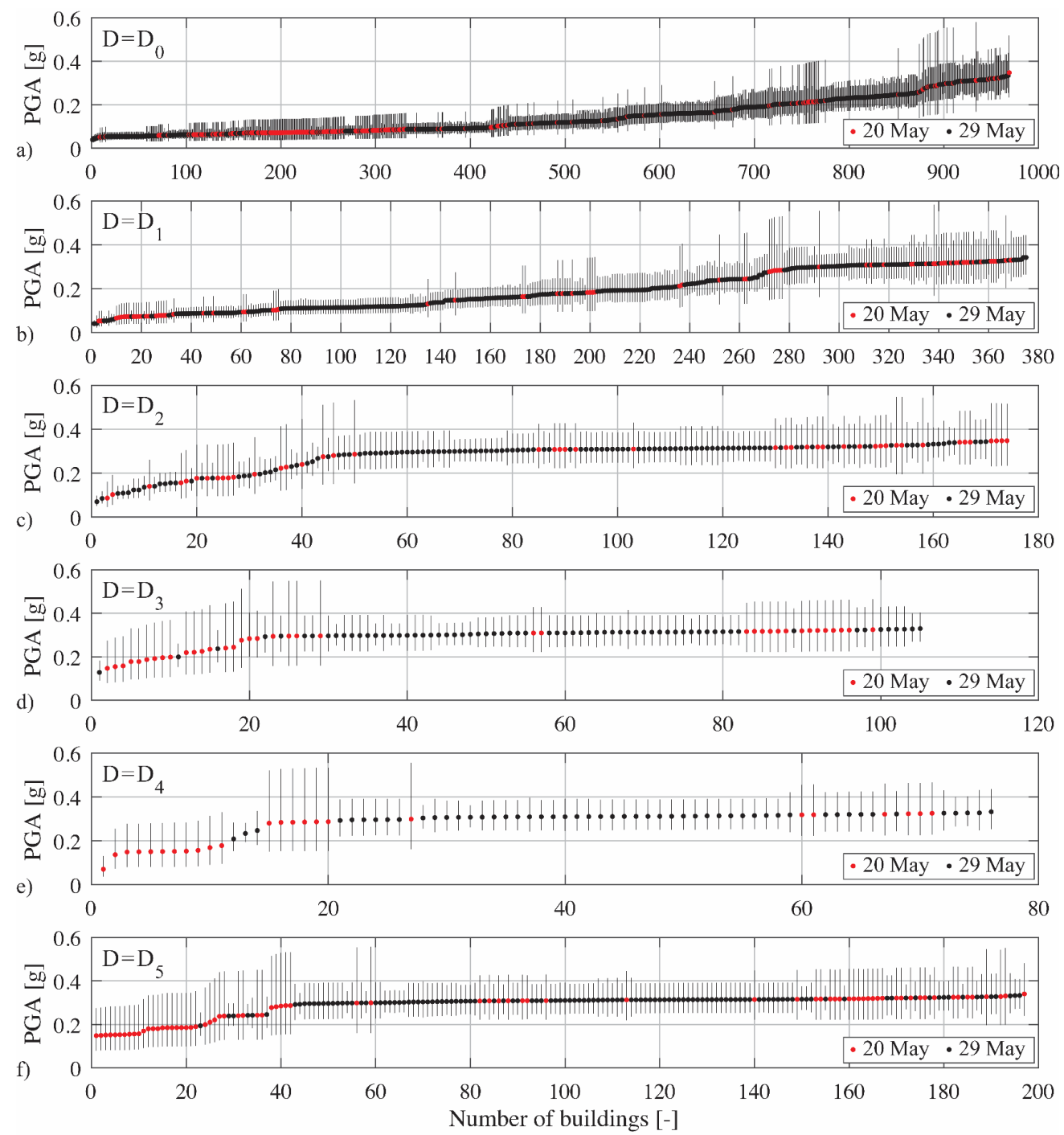

Fig. 8. Dataset used for the ordinal regression. Figures a) to f) correspond to damage levels $D_{0}$ to $D_{5}$, respectively. Each point represents the median PGA value assigned to a building, colours indicate the earthquake that produced the ground-motion (20 May and 29 May). Vertical bars represent \pm standard deviation intervals on the logarithm of PGA, centred on the median PGA value.

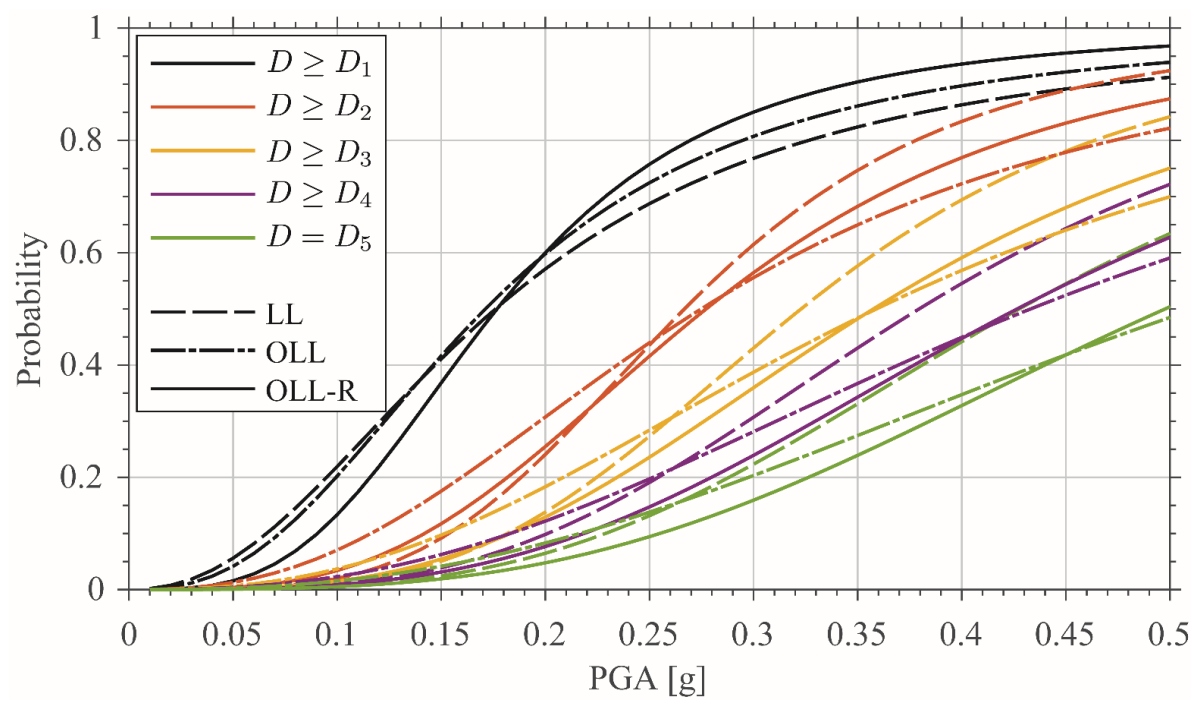

Fig. 9. Comparison of fragility curves obtained from the log-logit models (LL), the ordinal loglogistic model (OLL) and the ordinal log-logistic model taking ground-motion uncertainty into account (OLL-R). 
Finally, comparing the fragilities presented in the present work with those available in the literature for cast in place RC frame structures, e.g. [1], it is easy to notice the much higher vulnerability of prefabricated structures, especially as far as the most severe damage levels are considered $\left(D_{3}, D_{4}\right.$ and $\left.D_{5}\right)$. For example, in Figure 5(c) of [1], providing fragility curves for European-type RC buildings derived from a large observational dataset, the PGA values corresponding to $50 \%$ failure probability for the "Extensive", "Partial Collapse", and "Collapse" damage states are $1.65 \mathrm{~g}, 2.11 \mathrm{~g}$, and $2.27 \mathrm{~g}$, respectively. On the contrary, the PGA values corresponding to $50 \%$ failure probability for the fragility curves proposed in the present paper for damage states $D \geq D_{3}, D \geq D_{4}$ and $D=D_{5}$ are as low as $0.36 g, 0.43 g$, and $0.50 g$, respectively.

\section{CONCLUSIONS}

A database of seismic damage on 1890 precast RC buildings was assembled using data collected after the 2012 Emilia earthquake. Both field surveys and information provided by structural engineers appointed, by owners, to design retrofit/strengthening interventions for damaged buildings were used. The consistency of the building database was analysed using cadastral data as reference.

The damage was classified on a five level scale derived from EMS-98. Damage matrices were evaluated from the database and observational parametric fragilities were computed using a simulation based Bayesian approach. Two different classes of models were fitted: 1) models considering the different damage levels independently and ii) an ordinal logistic model which leads to non-overlapping fragility curves. In fact, being the dataset limited to $0.35 \mathrm{~g}$, fragility curves obtained from the individual damage states were slightly overlapped for larger PGA values. Furthermore, uncertainty on PGA was discussed and included in the ordinal model adopting a Berkson error model.

The fragility curves obtained in the present work, when compared to literature fragilities for cast in place RC frame buildings, indicate that precast industrial buildings are significantly more vulnerable. Therefore, specific fragility models should be used for assessing the seismic risk related to prefabricated buildings.

Finally, it should be noted that Emilia earthquakes caused PGA values not larger than $0.35 \mathrm{~g}$ and no information was available on the behaviour of the buildings under consideration for stronger ground-motions. Therefore, the fragility curves obtained, in particular those related to the most severe damage states considered could be biased, and should be used with care for stronger ground-motions. Nevertheless, the fragility models presented may provide important information for validating fragility curves obtained from numerical models.

\section{ACKNOWLEDGEMENTS}

The present investigation was developed within the activities of the (Italian) University Network of Seismic Engineering Laboratories-ReLUIS in the research program funded by the (Italian) National Civil Protection- Progetto Esecutivo 2016 - Research Line "Reinforced Concrete Structures", WP2. The cadastral data reported in Section 2.2 were provided by the Italian Revenue Agency Observatory of the real estate market. The damage data were made available by the Emilia-Romagna region.

\section{REFERENCES}

[1] Rossetto T, Elnashai A. Derivation of vulnerability functions for European-type RC structures based on observational data. Eng Struct 2003; 25(10):1241-63.

[2] D'Ayala D, Spence R, Oliveira C, Pomonis A. Earthquake loss estimation for Europe's historic town centres. Earthq Spectra 1997; 13(4):773-93.

[3] Yamaguchi N, Yamazaki F. Fragility curves for buildings in Japan based on damage surveys after the 1995 Kobe earthquake. Proceedings of the 12th World Conference on Earthquake Engineering, Auckland, New Zealand, January 30 - February 4, 2000.

[4] Karababa FS, Pomonis A. Damage data analysis and vulnerability estimation following the August 14, 2003 Lefkada Island, Greece, Earthquake. Bull Earthq Eng 2011; 9(4):1015-46.

[5] Spence RJS, Coburn AW, Sakai S, Pomonis A. A parameterless scale of seismic intensity for 
use in the seismic risk analysis and vulnerability assessment. Proceedings of the International Conference on Earthquake, Blast and Impact, Manchester, United Kingdom, September 18-20, 1991.

[6] Orsini G. A model for building's vulnerability assessment using the Parameterless Scale of seismic Intensity (PSI). Earthq Spectra 1999; 15(3):463-83.

[7] Molina S, Torres Y, Benito B, Navarro M, Belizaire D. Using the damage from 2010 Haiti earthquake for calibrating vulnerability models of typical structures in Port-au-Prince (Haiti). Bull Earthq Eng 2013; 12(4):1459-78.

[8] Hancilar U, Taucer F, Corbane C. Empirical fragility functions based on remote sensing and field data after the 12 January 2010 Haiti earthquake. Earthq Spectra 2013; 29(4):1275-310.

[9] Rota M, Penna A, Strobbia CL. Processing Italian damage data to derive typological fragility curves. Soil Dyn Earthq Eng 2008; 28(10-11):933-47.

[10] Colombi M, Borzi B, Crowley H, Onida M, Meroni F, Pinho R. Deriving vulnerability curves using Italian earthquake damage data. Bull Earthq Eng 2008; 6(3):485-504.

[11] Rossetto T, Iannou I, Grant DN. Existing empirical fragility and vulnerability functions: Compendium and guide for selection. GEM Technical Report 2013-X, GEM Foundation, Pavia, Italy, 2013. Available at www.globalquakemodel.org.

[12] Crowley H, Pinho R, Bommer JJ. A probabilistic displacement-based vulnerability assessment procedure for earthquake loss estimation. Bull Earthq Eng 2004; 2(2):173-219.

[13] Buratti N, Ferracuti B, Savoia M. Response Surface with random factors for seismic fragility of reinforced concrete frames. Structural Safety 2010; 32(1):42-51.

[14] Erberik MA. Fragility-based assessment of typical mid-rise and low-rise RC buildings in Turkey. Eng Struct 2008; 30:1360-74.

[15] Porter KA. An Overview of PEER's Performance-Based Earthquake Engineering Methodology. 9th International Conference on Applications of Statistics and Probability in Civil Engineering, San Francisco, CA, U.S., July 6-9, 2003.

[16] Silva V, Crowley H, Varum H, Pinho R, Sousa R. Evaluation of analytical methodologies used to derive vulnerability functions. Earthquake Engng Struct Dyn 2014; 43(2):181-204.

[17] Italian Revenue Agency. Observatory of the real estate market, www.agenziaentrate.gov.it, 2014.

[18] Nuti C, Vanzi I. Retrofitting of industrial structure. International Seminar and Exhibition on Recent Developments in Design and Construction for Precast Concrete Technology REDECON 2014, Bangalore, India, November 9-13, 2014.

[19] Tullini N, Minghini F. Grouted sleeve connections used in precast reinforced concrete construction - Experimental investigation of a column-to-column joint. Engineering Structures 2016; 127: 784-803.

[20] Bellotti D, Casotto C, Crowley H, Deyanova MG, Germagnoli F, Fianchisti G, Lucarelli E, Riva S, Nascimbene R. Single-storey precast buildings: probabilistic distribution of structural systems and subsystems from the sixties. Progettazione Sismica 2014; 5(3):41-70 (in Italian).

[21] Casotto C, Silva V, Crowley H, Nascimbene R, Pinho R. Seismic fragility of Italian RC precast industrial structures. Eng Struct 2015; 94:122-36.

[22] Legislative Decree 74/2012. Interventi urgenti in favore delle popolazioni colpite dagli eventi sismici che hanno interessato il territorio delle province di Bologna, Modena, Ferrara, Reggio Emilia, Mantova e Rovigo, il 20 e 29 maggio 2012. Rome, Italy, 2012. Available at http://www.cgm3esse.com/normativa/terremoto-emilia/testi-integrali (in Italian).

[23] Dolce M, Di Bucci D. National Civil Protection organization and technical activities in the 2012 Emilia earthquakes (Italy). Bull Earthq Eng 2014; 12(5):2231-53.

[24] Bonfanti C, Carabellese A, Toniolo G. Strutture prefabbricate: catalogo delle tipologie esistenti. Report of the (Italian) University Network of Seismic Engineering Laboratories-ReLUIS, February 2008. Available at www.reluis.it (in Italian).

[25] Mandelli Contegni M, Palermo A, Toniolo G. Strutture prefabbricate: schedario di edifici prefabbricati in c.a. Report of the (Italian) University Network of Seismic Engineering Laboratories-ReLUIS and the National Association of Industrial Concrete ProductsASSOBETON, May 2008. Available at unina.stidue.net (in Italian).

[26] Savoia M, Mazzotti C, Buratti N, Ferracuti B, Bovo M, Ligabue V, Vincenzi L. Damages and 
collapses in industrial precast buildings after the Emilia earthquake. Ingegneria Sismica: International Journal of Earthquake Engineering 2012; 29(2-3):120-31.

[27] Liberatore L, Sorrentino L, Liberatore D, Decanini LD. Failure of industrial structures induced by the Emilia (Italy) 2012 earthquakes. Eng Fail Anal 2013; 34:629-47.

[28] Bournas DA, Negro P, Taucer F. Performance of industrial buildings during the Emilia earthquakes in Northern Italy and recommendations for their strengthening. Bull Earthq Eng 2014; 12(5):2383-404.

[29] Biondini F, Dal Lago B, Toniolo G. Role of wall panel connections on the seismic performance of precast structures. Bull Earthq Eng 2013; 11(4):1061-81.

[30] Baggio C, Bernardini A, Colozza R, Corazza L, Della Bella M, Di Pasquale G et al. Guide to filling in the 1st level form for damage survey, prompt interventions and usability of ordinary buildings in the post-earthquake emergency (AeDES). Italian Department of Civil Protection (ed), Rome, Italy, 2000 (in Italian).

[31] Emilia-Romagna Regional Decree 57/2012. Available at http://www.regione.emiliaromagna.it/terremoto/gli-atti-per-la-ricostruzione?b_start:int=0 (in Italian).

[32] Minghini F, Ongaretto E, Ligabue V, Savoia M, Tullini N. Observational failure analysis of precast buildings after the 2012 Emilia earthquakes. Earthquakes and Structures 2016; 11(2):327-46.

[33] EMS-98. European Macroseismic Scale 1998. In: Grünthal G (ed) Cahiers du Centre Européen de Géodynamique et de Séismologie, Vol. 15, Luxemburg, 1998.

[34] Braga F, Gigliotti R, Monti G, Morelli F, Nuti C, Salvatore W, Vanzi I. Speedup of post earthquake community recovery: the case of precast industrial buildings after the Emilia 2012 earthquake. Bull Earthq Eng 2014; 12(5):2405-18.

[35] Italian National Institute of Geophysics and Volcanology (INGV). ShakeMap Home Page, http://shakemap.rm.ingv.it/shake/index.html, 2012.

[36] Cultrera G, Faenza L, Meletti C, D’Amico V, Michelini A, Amato A. Shakemaps uncertainties and their effects in the post-seismic actions for the 2012 Emilia (Italy) earthquakes. Bull Earthq Eng 2014; 12(5):2147-64.

[37] Braga F, Gigliotti R, Monti G, Morelli F, Nuti C, Salvatore W, Vanzi I. Post-seismic assessment of existing constructions: evaluation of the shakemaps for identifying exclusion zones in Emilia. Earthquakes and Structures 2015; 8(1):37-56.

[38] NTC08. Italian Building Code-D.M. 14/01/2008. Rome, Italy, 2008 (in Italian).

[39] O'Rourke MJ, So P. Seismic fragility curves for on-level steel tanks. Earthq Spectra 2000; 16(4):801-15.

[40] Lallemant D, Kiremidjian A, Burton H. Statistical procedures for developing earthquake damage fragility curves. Earthquake Engng Struct Dyn 2015; doi: 10.1002/eqe.2522.

[41] Gelman A, Carlin JB, Stern HS, Dunson DB, Vehtari A, Rubin DB. Bayesian Data Analysis. 3rd ed. Chapman \& Hall/CRC Press; 2013.

[42] Koutsourelakis PS, Pradlwarter HJ, Schuëller GI. Reliability of structures in high dimensions. Proceedings in Applied Mathematics and Mechanics 2003; 3(1): 495-496.

[43] Shinozuka M, Feng MQ, Lee J, Naganuma T. Statistical Analysis of Fragility Curves. Journal of Engineering Mechanics 2000; 126(12): 1224-1231.

[44] R Development Core Team. R: A Language and Environment for Statistical Computing. Vienna, Austria: R Foundation for Statistical Computing; 2008.

[45] Plummer M. JAGS: A Program for Analysis of Bayesian Graphical Models Using Gibbs Sampling. Proceedings of the 3rd International Workshop on Distributed Statistical Computing, Wien, Austia, 20-22 March: 2003.

[46] Jackman S. Bayesian Analysis for the Social Siences. John Wiley \& Sons; 2009.

[47] Agresti A. Analysis of ordinal categorical data. Wiley; 2010.

[48] Straub D, Der Kiureghian A. Improved seismic fragility modeling from empirical data. Structural Safety 2008; 30(4): 320-336.

[49] Carroll RJ, Carroll RJ. Measurement error in nonlinear models: a modern perspective. Chapman \& Hall/CRC; 2006.

[50] Worden C., Wald DJ. ShakeMap Manual Online: technical manual, user's guide, and software guide. 2016. DOI: 10.1234/012345678. 
